\section{Electric-Field-Driven Jetting Phenomenon Applied to Process Living Cells}

Although recent advances have made inkjet printing of biological samples possible, concentrated suspensions pose a problem: the lower limit of the droplet diameter is about twice the internal diameter of the needle orifice, resulting in blockage in needles with diameters of $30 \mu \mathrm{m}$ or less for the production of $\sim 60 \mu \mathrm{m}$ droplets. In practice, inkjet printing has a resolution of $\geq 100 \mu \mathrm{m}$ due to droplet spreading.

Electrohydrodynamic jetting (EHDJ), also known as electrospraying or electrostatic atomization, however, has been shown to produce droplets in the nanometer-tomicrometer size range from concentrated suspensions. In EHDJ, a charged medium exiting a needle enters a high-intensity electric field, thereby producing jets, which then initiate droplet formation through nonlinear processes. In inkjet printing, by contrast, a current is used to flex a piezoelectric crystal within a needle, thereby promoting droplet formation or, alternatively, ultrasound is used to create waves that generate droplets. Recently, researchers from the Mechanical Engineering Department at University College London and the Randall Division of Cell and Molecular Biophysics at Kings College

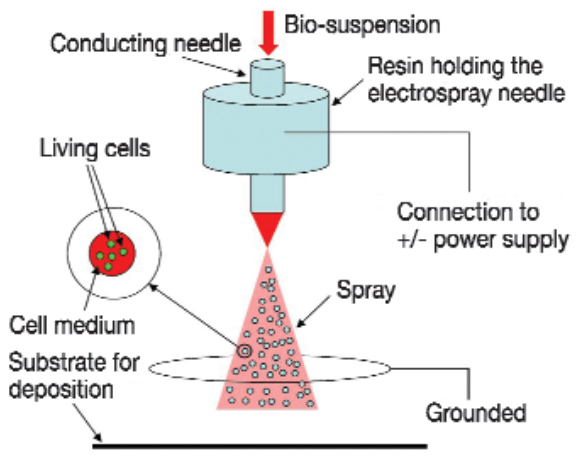

Figure 1. Schematic of the electro-

hydrodynamic jetting equipment.

London have demonstrated that EHDJ can be used to deposit living cells in suspension onto surfaces in droplets $<40 \mu \mathrm{m}$ in diameter $(<100 \mu \mathrm{m}$ after spreading). Moreover, the cells remain intact and viable after electrospraying.

As reported in the February issue of Small (DOI:10.1002/smll.200500291; p. 216), University College London researcher S.N. Jayasinghe and Kings College London researchers A.N. Qureshi and P.A.M. Eagles electrosprayed a suspension of Jurkat cells (a common cell line derived from human T-cell leukemia) using the apparatus shown in Figure 1. The medium was charged by syringing at a flow rate of $10^{-8} \mathrm{~m}^{3} \mathrm{~s}^{-1}$ through a needle kept at positive potential with respect to the ground electrode and was immediately dispersed upon entering the external electric field $0.85 \mathrm{kV} \mathrm{mm}^{-1}$ in strength. Sparks discharging between the needle and the ground electrode were observed periodically. The polydisperse droplet size distribution, which was measured by a laser spectrometer, showed large peaks at $\sim 17 \mu \mathrm{m}$ and $\sim 37 \mu \mathrm{m}$. The researchers used a $40 \times$ phase objective on an inverted microscope to examine the electrosprayed sample and observed that the cells appeared normal. About $2 \mathrm{~h}$ after electrospraying, optical microscopy revealed no signs of cellular damage. Incubation of several samples of electrosprayed cells for $24 \mathrm{~h}$ showed no adverse affects on cell division. The researchers also took samples of other types of cells (including primary cells) through a similar electrospraying protocol and found no adverse effect on the cells' structure, activity, or rate of division.

The researchers said that "the electrohydrodynamic jet processing phenomenon is strongly placed for competing with inkjet technology in the race to develop biological tissues for repair."

STEVEN TROHALAKI

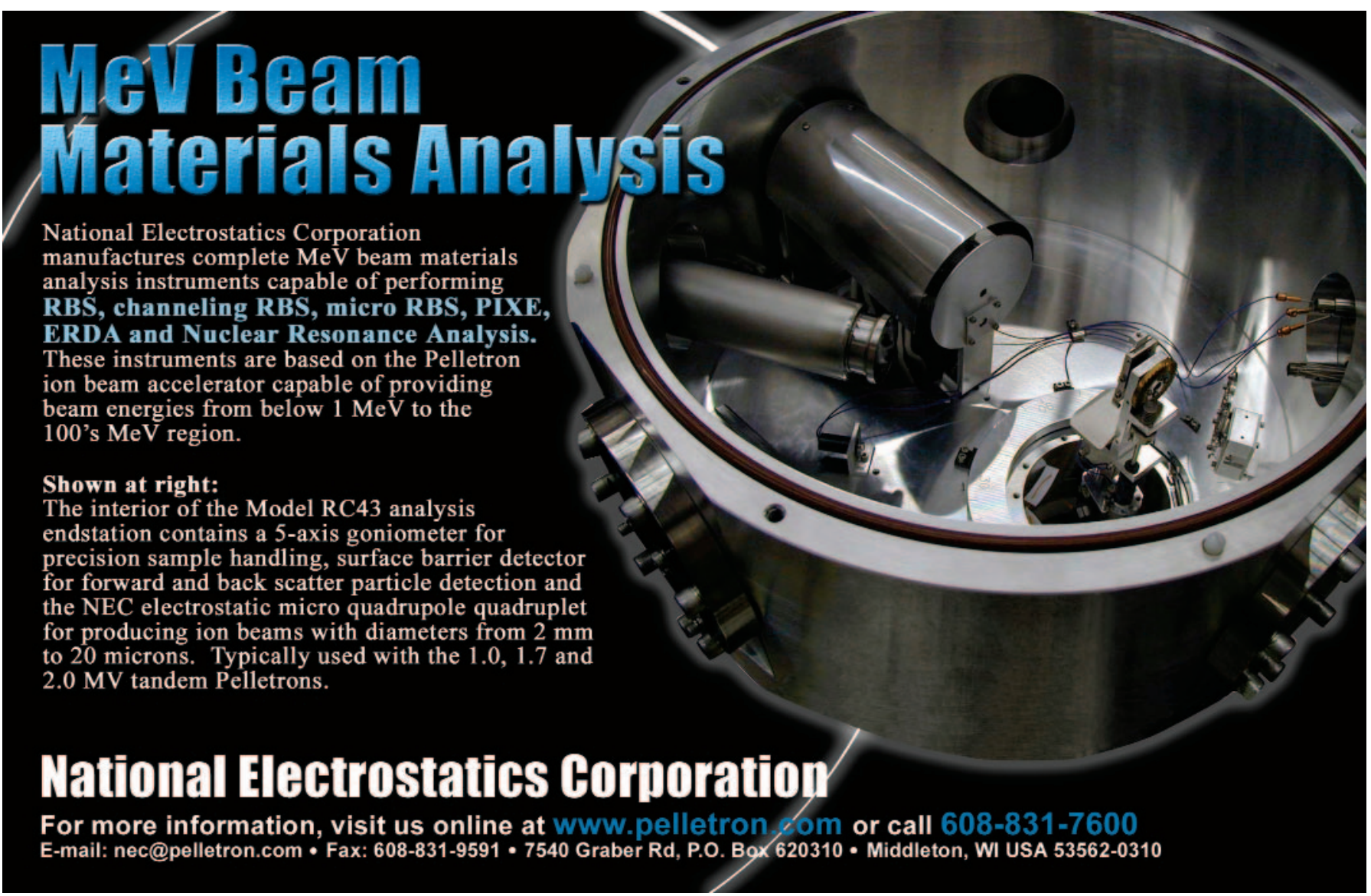

For more information, see http://www.mrs.org/bulletin_ads 